\section{The Cambridge Symposium: Glaucoma}

Peter Watson and John Cairns have made ophthalmology in Cambridge a powerhouse for investigations into the diagnosis and management of glaucoma. The annual autumnal meeting at St John's College gives a splendid opportunity to cover one subject in depth, and it seemed appropriate, some three decades after the introduction of guarded filtration surgery for glaucoma, to review current treatments and concepts of the disease.

September 1999 saw the assembling of a world-class team of glaucomatologists to address these issues. Day one looked at basic ideas: terminology, genetics, anatomy, blood flow and neuroprotection, closing with a philosophical review of the role of resetting

intraocular pressure in management. Day two began with the trabecular meshwork and aqueous humour before revisiting genetics (that modern star of glaucoma evaluation) and passing on to therapies.

The presentations resulted in lively, provocative and insightful discussions giving added flavour to the distilled knowledge presented by the speakers. It will be the sound of those discussions that will last longest in the ears of the audience, while the written text, reproduced in this issue of Eye, will act as the stimulus for further work. It will be the results of that work which are likely to be presented at the next Cambridge meeting devoted to glaucoma.

R.A. Hitchings, FRCS, FRCOphth 

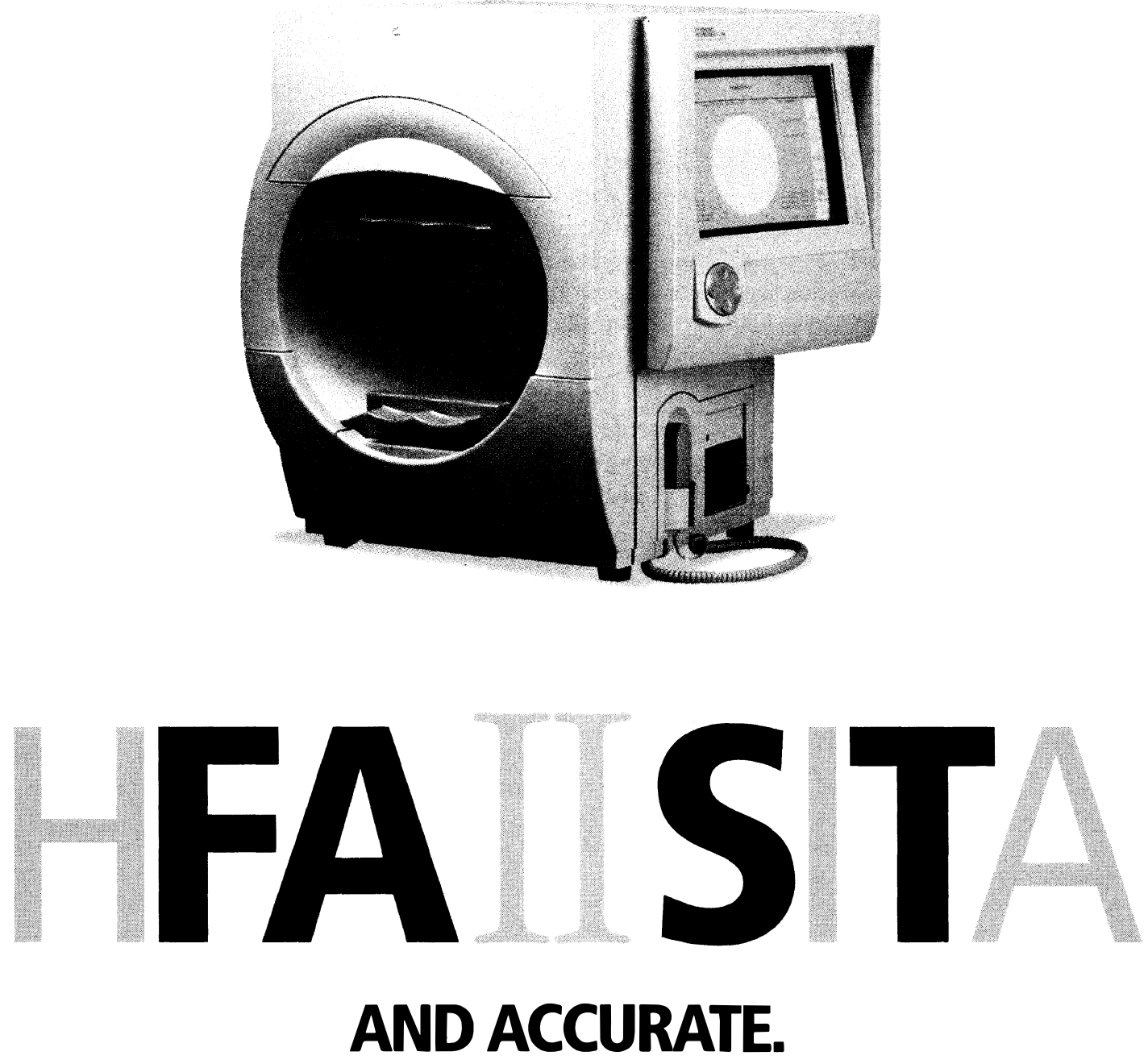

The Humphrey ${ }^{\oplus}$ Field Analyser II with SITA Built-in speed with even greater accuracy.

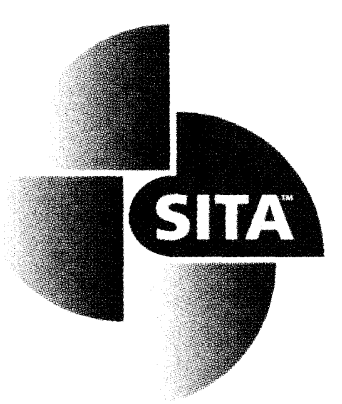

Carl Zeiss Ltd.

Medical Division

$41^{8}$ Internet: http://www.zeiss.co.uk
PO Box 78, Woodfield Road

Welwyn Garden City, Herts. AL7 1LU

Tel: 01707871350

Fax: 01707871287

E-mail: medinfo@zeiss.co.uk

\section{ZEINS}

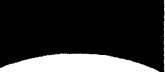

Humphrey Systems

A New Generetion in Ophthelmic Innovation 